\title{
Normal-tension glaucoma: an update
}

\section{Glaucoma de pressão normal: atualização}

Bruno Leonardo Barranco Esporcatte ${ }^{1}$, Ivan Maynart Tavares ${ }^{1}$

\section{ABSTRACT}

Normal-tension glaucoma (NTG) is a progressive optic neuropathy with intraocular pressure (IOP) within the statistically normal range $(\leq 21 \mathrm{mmHg})$. The prevalence of NTG varies widely among different population studies, being the most prevalent open-angle glaucoma subtype in some reports. The etiology of NTG possibly is multifactorial and still not well defined. Alternative treatments have been proposed based on pathogenesis details. However, in clinical practice, adequate reduction of IOP remains the keystone of managing patients with NTG. We review the pathogenesis of NTG and the available therapies for this optic neuropathy.

Keywords: Open-angle glaucoma; Intraocular pressure; Optic nerve diseases; Antihypertensive agents/therapeutic use

\section{RESUMO}

O glaucoma de pressão normal (GPN) é uma neuropatia óptica progressiva que cursa com a pressão intraocular (PIO) dentro da faixa de normalidade ( $\leq 21 \mathrm{mmHg}$ ). A prevalência do glaucoma de pressão normal varia entre os estudos populacionais, sendo em alguns o principal subtipo de glaucoma primário de ângulo aberto. A etiologia do glaucoma de pressão normal possivelmente é multifatorial e ainda não foi totalmente esclarecida. Tratamentos alternativos baseados nos diferentes detalhes da patogenia foram recentemente propostos. Entretanto, na prática clínica, a redução adequada da pressão intraocular continua sendo a base do tratamento do glaucoma de pressão normal. O objetivo deste artigo é revisar a patogênese do glaucoma de pressão normal e as formas de terapia disponíveis.

Descritores: Glaucoma de ângulo aberto; Pressão intraocular; Doenças do nervo óptico; Anti-hipertensivos/uso terapêutico

\section{INTRODUCTION}

Normal-tension glaucoma (NTG) is a progressive optic neuropathy similar to primary open-angle glaucoma (POAG); however, NTG does not present with intraocular pressure (IOP) outside the statistically normal range. It has been difficult to conceptualize the disease entity of NTG, even more so after the removal of IOP from the description of glaucomatous optic neuropathy $(\mathrm{GON})^{(1,2)}$ and after the understanding of the influence of central corneal thickness (CCT) in IOP measurements ${ }^{(3)}$. Moreover, publications on the subject are ambiguous and it is almost impossible to compare them.

Both glaucoma phenotypes have normal anterior chamber angles, peripapillary retinal nerve fiber layer (RNFL) thinning, GON, and corresponding visual field (VF) defects ${ }^{(4,5)}$. Because of these similarities, it has been postulated that NTG and high-pressure POAG represent a continuum of open-angle glaucomas and differ basically in the importance of IOP on the development and progression of the disease ${ }^{(5)}$. Therefore, it is crucial to define glaucoma based on the characteristics of the optic nerve and not to use a single risk factor, IOP, to distinguish among the various conditions of GON(1).

However, several structural and functional differences support the fact that different mechanisms may have a stronger role in the pathogenesis of NTG versus high-pressure POAG. Also, a recent study reported genetic variants associated with different tendencies towards POAG with lower or higher IOP(6). Furthermore, clinical impression and anecdotal evidence suggest that NTG with mean IOP in the high teens $(>15 \mathrm{mmHg}$ ), in which circadian fluctuation and CCT could lead to a possible misdiagnosis of an IOP $\leq 21 \mathrm{mmHg}$, would differ from NTG with mean IOP in the low teens $(\leq 15 \mathrm{mmHg})$, with different pathogenesis and progression patterns, harder to achieve target IOP and higher incidence of disc hemorrhages. Nonetheless, a recent report does not support this assumption and underscores low-teens NTG as an important entity ${ }^{(7)}$.

The proportion of NTG varies depending on different population studies. In Asian epidemiological protocols, NTG constituted the majority of open-angle glaucomas (52\%-92\%), depending on the country and study methodology ${ }^{(8)}$. Normal IOP was measured in $57.1 \%$ cases of POAG in a South African study ${ }^{(9)}$. In white populations, the proportion of NTG was lower than that observed in Asian and African populations. In studies conducted in the United States, Netherlands, and Italy, NTG presented proportions of 31.7\%, 38.9\%, and $30 \%$, respectively ${ }^{(10-12)}$

The etiology of NTG is most likely multifactorial and still not wel defined. Moreover, several alternative treatments based on this different pathogenesis have been discussed. The objective of this study was to review the mechanisms involved in the onset and progression of NTG and the efficacy of established and alternative therapies for NTG treatment.

\section{Pathogenesis}

The pathogenesis of NTG is unclear, and perhaps the development of the disease is a consequence of a complex interaction of several systemic and ocular factors. Different studies have shown that the cardiovascular system and intracranial pressure may be involved in the main pathways of optic nerve damage. Nevertheless, the complex relationship between these mechanisms and glaucoma progression continues to be debated.
Submitted for publication: January 11, 2016

Accepted for publication: April 15, 2016

Glaucoma Division, Department of Ophthalmology and Visual Sciences, Escola Paulista de Medicina, Universidade Federal de São Paulo, São Paulo, SP, Brazil.
Funding: No specific financial support was available for this study.

Disclosure of potential conflicts of interest: None of the authors have any potential conflict of interest to disclose.

Corresponding author: Ivan M. Tavares. Rua Botucatu, 821 - São Paulo, SP - 04023-062 - Brasil E-mail: im.tavares@unifesp.br 


\section{Nocturnal systemic hypotension}

A systematic review and meta-analysis on the involvement of circadian variations in arterial blood pressure (BP) and GON was performed, including information about high-pressure POAG and NTG patients. There was no difference in the mean systolic or diastolic diurnal and nocturnal BP between patients with or without progression of VF defects. Nocturnal dips greater than $10 \%$ of daily systolic or diastolic BP were a risk factor for progressive VF loss. However, the data published do not allow a differentiation between physiological dipping and over-dipping as a risk factor for glaucomatous optic neuropathy ${ }^{(13)}$.

A prospective study including only NTG patients monitored the arterial BP every 30 min over a 48-h period for the baseline and at the 6- and 12-month follow-up visits. Of 85 patients enrolled, 29\% had VF progression, and a multivariate analysis showed that the duration and magnitude of decrease in nocturnal BP during sleep, particularly $10 \mathrm{mmHg}$ lower than daytime BP, predicted VF progression ${ }^{(14)}$.

The correlation between a pronounced fall in BP during sleep and progressive glaucomatous damage can be explained by ischemic insults to the optic nerve generated by low ocular perfusion. The ocular perfusion pressure (OPP) is an indirect measurement calculated with arterial BP and IOP. In NTG patients, significant dips in BP during sleep and OPP were the risk factors for the severe progression of $\mathrm{VF}$ dama$\mathrm{ge}^{(15)}$. The fluctuation of mean OPP also correlated with VF damage progression. In a retrospective study, each 1-mm increase in mean OPP fluctuation was associated with a $27.2 \%$ greater chance of glaucoma progression during a follow-up period of $73.1 \pm 11.2$ months $^{(16)}$.

\section{Autonomic dysfunction}

The circadian variations of BP are regulated by sympathetic neural activity. This system is responsible for the increase in heart rate, stroke volume, and vasoconstriction. A chronic imbalance of sympathetic and parasympathetic activity, with a predominance of the sympathetic system, leads to arterial and cardiac remodeling, endothelial dysfunction, decrease in local blood flow, and increase in tissue oxygen demand ${ }^{(17)}$.

Patients with NTG present with sympathovagal balance of the autonomic nervous system that has been shifted towards sympathetic activity ${ }^{(18,19)}$. Patients with a low heart rate variability, which reflects autonomic dysfunction with sympathetic predominance, had a greater risk for central VF damage progression than patients with a high heart rate variability ${ }^{(20)}$.

Primary vascular dysfunction or Flammer syndrome was also correlated with NTG. This syndrome was characterized by an insufficient or improper adaption of blood flow, despite the presence of anatomically healthy vessels and the absence of a causative disease, and results in a transiently incorrect blood supply for the tissue needs. The leading symptoms include cold hands and/or feet, low BP with pronounced fall at night, prolonged sleep onset time, shifted circadian rhythm, and reduced feeling of thirst. This presentation is more common in women, slender subjects, and Asians ${ }^{(21-23)}$.

\section{Obstructive sleep apnea/hypopnea}

Another cause of imbalance in ocular perfusion that may lead to GON is the obstructive sleep apnea/hypopnea syndrome(24). This syndrome is characterized by recurrent complete or partial upper airway obstruction during sleep. The obstructive respiratory disturbance may last up to $2 \mathrm{~min}$, leading to severe hypoxia and hypercapnia. A higher prevalence of NTG was reported in a cohort of patients with obstructive sleep apnea/hypopnea syndrome. The severity of the disease was inversely correlated with RNFL thickness ${ }^{(25)}$.

\section{Blood rheology impairment}

The deterioration of the optic nerve caused by oxygen inadequacy could also be provoked by a disturbance in the physical properties of blood flow. Other pathological conditions, such as myocardial infarction ${ }^{(26)}$, stroke ${ }^{(27)}$, and diabetes mellitus with peripheral circulation disorders ${ }^{(28)}$, were correlated with abnormal hemorheological proprieties

Patients with NTG showed several abnormal blood parameters compared with normal subjects. The first group presented with higher blood viscosity, erythrocyte aggregability, flow resistance of erythrocytes, and poor erythrocyte deformability. All of these parameters represent low blood oxygen transport efficiency and may result in hypoperfusion of the optic nerve ${ }^{(29,30)}$.

\section{INTRACRANIAL PRESSURE}

A mechanical theory was proposed for the development of NTG. The lamina cribrosa is a thin area of scleral tissue, which separates two pressurized compartments, the intraocular and orbital subarachnoid spaces. It was hypothesized that an elevated posteriorly-directed pressure differential contributes to optic nerve damage and produces a posterior displacement of the lamina cribrosa ${ }^{(31)}$. Conversely, increased posterior pressure presented an anteriorly directed pressure vector, associated with intracranial hypertension, that could cause papilledema ${ }^{(32)}$

The cerebrospinal fluid pressure was significantly lower in the NTG $(9.5 \pm 2.2 \mathrm{mmHg})$ than in high-pressure POAG $(11.7 \pm 2.7 \mathrm{mmHg}$, $P=0.013)$ and control group $(12.9 \pm 1.9 \mathrm{mmHg}, P<0.001)$ eyes. The translamina cribrosa pressure difference (calculated as the difference of IOP minus cerebrospinal fluid pressure) was significantly higher in the high-pressure POAG $(12.5 \pm 4.1 \mathrm{mmHg})$ than in the NTG group $(6.6 \pm 3.6 \mathrm{mmHg}, P<0.001)$ and control group $(1.4 \pm 1.7 \mathrm{mmHg}$, $P<0.001)$ eyes. Moreover, the perimetric loss was positively correlated with the translamina cribrosa pressure difference in a multivariate analysis with both glaucoma groups ${ }^{(33)}$, and a negative correlation was found between this pressure and the neuroretinal rim area ${ }^{(34)}$.

A recent meta-analysis, which included the previously cited studies, concluded that intracranial pressure was significantly lower in patients with high-pressure POAG and NTG than in the control subjects. Moreover, compared with non-glaucoma patients, the translamina cribrosa pressure difference was almost two times higher in patients with NTG and five times higher in high-pressure POAG patients ${ }^{(35)}$.

\section{Clinical evaluation}

Several conditions could affect the optic nerve head and complicate the diagnosis of NTG. Ischemic optic and hereditary optic neuropathies, demyelinating optic neuritis, multiple sclerosis, trauma, intraocular infections, and intraorbital or intracranial mass with compressive effects on the optic nerve or chiasm have been reported to produce optic disc cupping and VF defects ${ }^{(36-39)}$, and these diseases do not present with elevated IOP.

There is insufficient evidence to recommend a routine neuroradiological evaluation in all NTG patients. However, young individuals with a significant decrease in visual acuity, vertically aligned VF defects, and neuroretinal rim pallor may present with anterior visual pathway compression caused by an intracranial mass, which should be evaluated with neuroimaging examinations ${ }^{(40,41)}$.

After eliminating all secondary causes of glaucoma and possible diseases that could lead to a misdiagnosis of NTG, it is important to evaluate the influence of CCT on IOP. A thin CCT underestimates the true IOP and can inaccurately classify a patient as having NTG $\mathrm{NT}^{(3,42,43)}$. Nonetheless, the relationship of CCT and glaucomatous structural damage severity or NTG progression is controversial(44-46).

Other corneal biomechanical properties may be related to optic nerve head damage in glaucoma. Hysteresis refers to the ability of the ocular connective tissues to dampen pressure changes. Eyes with a more deformable cornea, less viscous damping, and lower corneal hysteresis could have optic discs more susceptible to glaucoma damage 
from increased IOP(47-49). Corneal hysteresis measurements were significantly lower in patients with high-pressure POAG and NTG than in normal subjects ${ }^{(50)}$. Also, a faster progression of VF damage in NTG patients with low corneal hysteresis has been observed(51).

Vascular dysfunction in peripheral microcirculation was associated with central VF defects in NTG patients and could be evaluated by nail fold capillaroscopy ${ }^{(52)}$. Other systemic evaluations could be helpful to NTG suspects. Ambulatory BP monitoring could be performed to detect a pronounced decrease in BP during sleep, and sleep polysomnography could be used to diagnose obstructive apnea/ hypopnea cases.

\section{Structural differences between NTG and POAG \\ Optic disc}

Some differences exist in biomicroscopic features of optic nerve damage in NTG patients. The optic cups seem to be larger in patients with NTG than in those with high-pressure POAG. Moreover, the borders of the neuroretinal rims are not well defined and are saucerized and thinner, particularly in temporal and inferior zones ${ }^{(53,54)}$. Disc analysis with Heidelberg retina tomography (HRT) showed larger optic discs with larger and deeper cups in patients with NTG than in those with high-pressure POAG ${ }^{(55,56)}$.

\section{Macular ganglion cell complex}

In NTG patients, macular ganglion cell complex thickness and peripapillary RNFL thickness showed a similar ability to discriminate glaucomatous from normal eyes ${ }^{(57)}$.

Kim et al. compared the macular ganglion cell complex thickness of subjects with NTG and high-pressure POAG. For equivalent average peripapillary RNFL defects $(90.92 \pm 16.00$ and $84.00 \pm 14.49$, $P=0.053)$ and VF mean deviation (MD; -7.09 \pm 5.36 and $-7.70 \pm 4.40$, $P=0.746)$, the macular ganglion cell complex loss was more localized in the inferior hemifield in NTG patients and more diffused in the high-pressure POAG group ${ }^{(58)}$.

\section{Prelaminar tissue}

Jung et al. investigated the difference in prelaminar tissue thickness between patients with high-pressure POAG and NTG using enhanced depth imaging optical coherence tomography (OCT). The prelaminar tissue was significantly thinner in the high-pressure POAG group than in the NTG group, particularly in the early stages of the disease. The prelaminar thickness negatively correlated with IOP in both groups. Based on these results, they suggested that IOP was the main pathogenic factor in the nerve damage of patients with NTG and high-pressure POAG ${ }^{(59)}$.

\section{Lamina cribrosa}

The lamina cribrosa is apparently influenced by factors other than IOP only. Park et al. observed that NTG patients had a lower lamina cribrosa thickness than patients with high-pressure POAG, even in the early stages of the disease. In addition, patients with NTG who presented with disc hemorrhages during follow-up had a thinner lamina cribrosa than those without hemorrhage ${ }^{(60)}$.

Using enhanced depth imaging OCT, Kwun et al. investigated the lamina cribrosa thickness of patients with NTG who had unilateral VF defects. VF-affected eyes had a thinner lamina cribrosa than their corresponding eyes with a normal configuration. Although the normal corresponding eyes of NTG patients did not have any VF defects, glaucomatous optic nerve heads, or RNFL defects, their lamina cribrosa was thinner than that in normal control subject eyes ${ }^{(61)}$. Recently, Omodaka et al. reached similar conclusions using swept-source OCT to obtain a three-dimensional evaluation of the lamina cribrosa ${ }^{(62)}$

\section{Peripapillary scleral thickness}

In a study using a swept source OCT, in which scleral thickness in glaucomatous and non-glaucomatous myopic patients was compared, it was observed that the posterior sclera was significantly thinner in the inferior region of glaucomatous eyes with high myopia, and this was related to the degree of vertical tilt and torsion. This difference may be related to changes in the optic disc and/or susceptibility to glaucoma even with normal IOP and could contribute to glaucomatous changes in the corresponding region ${ }^{(63)}$.

\section{Choroidal thickness}

The choroidal supply to the papillary area could also be an etiological factor in glaucoma, particularly in NTG. However, the evaluation of choroidal thickness and its association with glaucoma show conflicting results. A cross-sectional study and meta-analysis in a Chinese cohort suggested that there was no relationship between choroidal thickness in the macular region and primary open-angle glaucoma ${ }^{(64)}$. Another study in an adult Chinese population, the Beijing Eye Study, also did not show an association between peripapillary choroidal thickness measurements and the presence of glaucoma ${ }^{(65)}$. Zhang et al. did not identify a relationship between peripapillary and macular choroidal thickness and the markers of severity of glaucoma (MD and RNFL thickness) ${ }^{(66)}$.

Using the enhanced depth imaging (EDI) OCT, Hirooka et al. observed a reduced choroidal thickness in the inferonasal, inferior, and inferotemporal regions in the NTG patients compared with that in normal subjects ${ }^{(67)}$. Park et al. compared the macular and peripapillary choroidal thickness of normal subjects and high-pressure POAG and NTG patients and found no significant differences in macular thickness among the groups. However, in their study, the average peripapillary choroidal thickness was significantly thinner in NTG $(147.01 \pm 35.31 \mu \mathrm{m})$ than in control $(226.35 \pm 39.52 \mu \mathrm{m}, P<0.001)$ and high-pressure POAG (200.11 $\pm 32.16 \mu \mathrm{m}, P<0.001)$ eyes. Significant differences in the peripapillary choroidal thickness were observed between high-pressure POAG and NTG eyes in early, moderate, and severe stages of glaucoma $(P=0.017, P<0.001$, and $P<0.001$, respectively), classified by the VF MD index ${ }^{(68)}$.

Furthermore, a possible association between glaucoma and reduced choroidal thickness has been reported, but it is not yet clear whether it is primary or secondary to glaucoma damage.

\section{Disc hemorRhage}

Disc hemorrhage is an important risk factor for the onset and progression of GON ${ }^{(69-73)}$, particularly in NTG. This finding is an isolated splinter-like or flame-shaped hemorrhage within or on the margin of the optic disc or in the peripapillary retina extending to the disc rim.

Although the pathogenesis of disc hemorrhage has not yet been completely elucidated, several risk factors were associated with its occurrence. A history of migraine, narrower neuroretinal rim width at the baseline, low mean arterial ocular perfusion pressure, and the use of systemic beta blockers were independent risk factors for the occurrence of disc hemorrhage in treated NTG patients ${ }^{(74)}$.

The occurrence of an enlarged RNFL defect was more frequent in NTG patients who presented with disc hemorrhage, and the location of the defect was in the same region as that of the disc hemorrhage $^{(75)}$. Using serial EDI-OCT, Lee et al. observed that deformation or disruption of the lamina cribrosa precedes the occurrence of disc hemorrhage. The comparison of post- and pre-disc hemorrhage images showed that alterations spatially correlated with the location of the disc hemorrhage ${ }^{(76)}$.

\section{VisuAl FIELD DEFECTS AND PROGRESSION}

Caprioli and Spaeth compared the VF defects of patients with NTG with different glaucoma phenotypes with elevated IOP (primary open-angle, pseudoexfoliative, and pigmentary glaucoma). In this 
protocol, patients with NTG showed significantly deeper and closer-to-fixation scotomas. In addition, the involvement of fixation did not depend on the extent and depth of the VF defect ${ }^{(77)}$.

Similarly, in another study, patients with NTG were compared to those with high-pressure POAG adjusted to the same level of structural damage to the optic nerve and peripapillary nerve fiber layer as detected by HRT. It was observed that patients with NTG had a higher percentage of abnormal points in the upper and lower central regions ${ }^{(78)}$.

The 24-2 VF test pattern points are spaced every $6^{\circ}$, and only four points fall within the central $8^{\circ}$. This region comprises more than $30 \%$ of the retinal ganglion cell area ${ }^{(79)}$. Traynis et al. suggested that 24-2 standard perimetry could miss defects detected on the 10-2 VF test, particularly in the early stages of RNFL damage ${ }^{\left({ }^{(80)}\right.}$. Therefore the 10-2 strategy should be included in the evaluation of patients with scotomas within the central $10^{\circ}$.

Patients with NTG and superior hemifield defects had significantly faster progression rates than patients with inferior hemifield defects, and the difference between the progression rates was more pronounced in the central and nasal zones ${ }^{(81)}$. In initial VF defects, no differences in progression rates were observed among patients with central scotomas compared with those with peripheral defects ${ }^{(82)}$.

A relationship between a preferred sleeping position and an asymmetric VF loss in NTG patients was reported. In this retrospective study, $66 \%$ of NTG patients with asymmetric VF loss presented a worse eye in their preferred lateral decubitus position ${ }^{(83)}$. A compressive effect on the eye globe with an increase in IOP or a reduction in perfusion of the optic nerve could be possible mechanisms to explain these results.

To study risk factors for the progression of the VF defect in patients with NTG, Lee et al. separated two groups according to IOP (above and below $15 \mathrm{mmHg}$ ). There was no difference in the progression rates between the two groups. In the group with pressure $>15 \mathrm{mmHg}$, IOP was a risk factor for progression. However, in the group with lower pressures, the presence of optic disc hemorrhages was the only risk factor, demonstrating that progression mechanisms are not exclusively dependent on pressure values ${ }^{(84)}$.

The risk factors for the progression of glaucomatous damage detected by the NTG Collaborative Study Group were female sex, migraine, and occurrence of optic disc hemorrhage ${ }^{(85,86)}$. Sakata et al., in a retrospective analysis of an NTG cohort treated with hypotensive eye drops, reported that the extension of myopia was a risk factor for VF damage progression and that this progression often occurred in the upper paracentral region ${ }^{(46)}$. The influence of myopia on the progression rate of NTG was not observed by Sohn et al. ${ }^{(87)}$.

Despite different clinical features, epidemiology, and genetics, the glaucoma phenotype is not an independent risk factor for VF progression after covariate adjustment for all different subtypes involved in the disease ${ }^{(88)}$.

\section{TREATMEnT}

The mainstream treatment for NTG is IOP reduction. The Collaborative Normal-Tension Glaucoma Study demonstrated that a 30\% IOP reduction favorably influenced the progression of this disease in glaucoma patients compared with untreated NTG controls. The favorable effect of IOP reduction in the treated group was found only when the impact of cataracts on VF progression was removed. Moreover, in the same study, even after achieving the expected IOP reduction, the disease continued to progress in $12 \%$ of patients $s^{(89,90)}$.

The most frequently prescribed antiglaucoma drugs used in monotherapy in several studies did not reach the pressure reduction suggested by the Collaborative Normal-Tension Glaucoma Study. Prostaglandin analogues (latanoprost and bimatoprost), beta-blockers, and alpha-adrenergic agonists reduced the pressure from $16 \%$ to $20 \%$ when used in monotherapy ${ }^{(91,92)}$. Among fixed combinations of drugs, the dorzolamide-timolol compound reduced $23.7 \%$ of base- line IOP, and combined brimonidine-timolol drops lowered IOP by $3.8 \mathrm{mmHg}(23 \%)$ after 12 weeks of use in NTG patients ${ }^{(93,94)}$.

The Low-pressure Glaucoma Treatment Study compared the effects of brimonidine and timolol in monotherapy for NTG. Brimonidine-treated patients were less likely to have VF progression despite known comparable IOP decreases ${ }^{(95)}$. Although these results should be interpreted carefully because of the high rates of discontinuation in the brimonidine group, the results suggested that brimonidine was relatively protective, possibly due to IOP-independent pathways. Hayreh et al. suggested that topical beta-blocker eye drops induce a significant drop in mean diastolic BP at night and that beta-blocker-treated NTG patients showed VF damage progression more frequently than those not receiving this class of eye drops ${ }^{(96)}$.

The neuroprotective effects of brimonidine have been described in some pre-clinical studies. To avoid the brimonidine IOP effect, the drug was administered intraperitoneally in rats with episcleral vein cauterization-induced glaucoma. Treated animals showed a lower rate of retinal ganglion cell loss after IOP elevation ${ }^{(97)}$. In an optic nerve crush model, Lindsey et al. observed a similar action of intraperitoneally administered brimonidine on RGC protection ${ }^{(98)}$.

Other drugs have shown neuroprotective benefits in experimental glaucoma models. Memantine, an inhibitor of glutamate flux through the $\mathrm{N}$-methyl-D-aspartate receptor, is clinically used in neurological disorders, such as Alzheimer's dementia. ${ }^{(99,100)}$ Although several preclinical studies have demonstrated that memantine had a neuroprotective effect ${ }^{(101-103)}$, a large randomized clinical trial failed to show the same effect in human glaucoma (data not published)(104). The Memantine Trial actually showed that the progression of disease was significantly lower in patients receiving the higher dose of memantine than those receiving the low dose. However, there was no significant benefit compared to patients receiving placebo(105).

Extracts of Ginkgo biloba have been suggested for many years to treat various conditions, particularly circulatory problems, Alzheimer's and other age-associated dementias, cerebral blood insufficiency, and schizophrenia ${ }^{(106)}$. Several studies have been conducted to test its potential as a neuroprotective and antioxidative drug and to understand the possible benefits in the management of neurological and vascular conditions ${ }^{(107)}$.

There is no consensus on the effects of G. biloba in NTG patients. Quaranta et al. reported that its administration for 4 weeks improved the VF MD index in preexisting VF damage in some individuals with NTG ${ }^{(108)}$. Lee et al. reported that a prolonged (72.1 \pm 16.4 months) administration of $G$. biloba slowed the progression of VF damage in patients with NTG, particularly in the superior central region ${ }^{(109)}$. In contrast, in a Chinese cohort in a randomized clinical trial with NTG patients, Guo et al. assessed the impact of G. biloba on preexisting VF defects and contrast sensitivity. In this study, no effects on VF and contrast sensitivity were observed after 4 weeks of use ${ }^{(110)}$.

Systematic reviews on the use of G. biloba as a treatment of intermittent claudication ${ }^{(111)}$, tinnitus ${ }^{(112)}$, multiple sclerosis ${ }^{(113)}$, age-related macular degeneration ${ }^{(114)}$, and neurodegenerative progression of Alzheimer's disease ${ }^{(115)}$ do not suggest a clear clinically significant benefit. More randomized clinical trials in different populations are necessary to verify the efficacy of G. biloba on NTG patients.

Furthermore, several drugs that act on ocular blood flow have been tested. Calcium channel blockers, such as nimodipine, normalized the retinal blood flow in NTG patients with vasospastic symptoms ${ }^{(116)}$ and increased the blood and choroidal flow ${ }^{(117)}$. However, its potential benefits must be validated in randomized clinical trials. Oral magnesium therapy seems to improve the VF MD index in NTG patients; however, there were no significant changes in ocular blood flow as seen in a prospective trial(118).

Recently, it was demonstrated that salicylic acid/aspirin exhibits the ability to suppress the translocation of glyceraldehyde 3-phosphate dehydrogenase (GAPDH) to the nucleus and cell death. GAPDH is a cytosolic enzyme that has a central role in the production of 
energy via glycolysis and participates in DNA repair and transcription; this is what makes it a major suspect in neurodegenerative diseases, including Alzheimer's, Parkinson's, and Huntington's diseases. Therefore, salicylic acid/aspirin may have a potential role in the treatment of a wide variety of diseases, including glaucoma ${ }^{(119)}$.

\section{Laser and surgical treatment}

Despite the low IOP after treatment, approximately $50 \%$ of patients with NTG had VF damage progression as detected by perimetry ${ }^{(120,121)}$. It is possible that patients with this condition have a lower threshold for IOP mechanical injury than those with other glaucoma phenotypes and that more substantial IOP reduction is often necessary compared with the one achieved with topical medications or trabeculoplasty.

Studies involving selective laser trabeculoplasty (SLT) and NTG showed that the average rate of reduction of IOP was $14.7 \%$, correlating with a reduction of $26.7 \%$ in the number of used drops. The successful predictors of SLT were an elevated IOP before the procedure and a higher pressure drop in the first week after the procedure ${ }^{(122)}$.

Most patients achieve the therapeutic target using antiglaucoma medications and laser trabeculoplasty. In eyes experiencing VF damage progression despite treatment and low IOP levels, a filtering surgery must be performed. The surgical approach in those patients presents a therapeutic challenge because of the need to achieve pressures of a single digit without occurrence of any hypotony-related complications. In a retrospective study, Iversen et al. and Schultz et al. reported that $90 \%$ of patients with NTG who underwent trabeculectomy achieved IOP of $<10 \mathrm{mmHg}$ at the 1-year follow-up, and the probability of success was $68 \%$ after 4 years. However, $53 \%$ of patients had postoperative complications, with hypotony being the most common ${ }^{(123,124)}$.

To avoid hypotony, Jayaram et al. performed a trabeculectomy with tight releasable sutures applied with the aim of observing no aqueous flow at the end of the procedure. Subconjunctival steroid, 5-fluorouracil injections, or slit-lamp needling were performed when necessary. The authors obtained more than 30\% of IOP reduction in $91.1 \%$ at 1 year of follow-up and $62.1 \%$ at 4 years. Early and late hypotony rates were $2.8 \%$ and $0.8 \%$, respectively.

Deep sclerectomy can be an option to trabeculectomy for progressive NTG patients. In this non-perforating technique, the intact inner trabecular meshwork offers sufficient resistance to flow avoiding severe hypotony. Suominen et al. performed a prospective comparison of patients who underwent deep sclerectomy with or without mitomycin-C (MMC) with a 12-month follow-up period. Both groups received a collagen implant under the scleral flap. Total success (more than $25 \%$ reduction of IOP) was achieved in $67 \%$ and $41 \%$ of eyes in the MMC and non-MMC groups, respectively. One digit IOP, with or without medication, was more frequent in the MMC than in the non-MMC groups (47\% vs. 9\%, $P=0.009)$. Hypotony was observed in $27 \%$ eyes of the MMC group at the early postoperative period. No eye in either group had hypotony at the 12-month postoperative visit(126).

\section{CONCLUSION}

The complex etiology of NTG is not yet completely understood; however, several studies presented differences between this disorder and high-pressure POAG. In clinical practice, the adequate reduction of IOP remains the keystone of managing NTG patients. Some alternative treatments must be tested further in randomized clinical trials to verify their therapeutic effects.

\section{REFERENCES}

1. Lee BL, Bathija R, Weinreb RN. The definition of normal-tension glaucoma. J Glaucoma. 1998;7(6):366-71
2. Weinreb RN, Aung T, Medeiros FA. The pathophysiology and treatment of glaucoma: a review. JAMA. 2014;311(18):1901-11

3. Morad Y, Sharon E, Hefetz L, Nemet P. Corneal thickness and curvature in normal-tension glaucoma. Am J Ophthalmol. 1998;125(2):164-8.

4. Mi XS, Yuan TF, So KF. The current research status of normal tension glaucoma. Clin Interv Aging. 2014;9:1563-71

5. Shields MB. Normal-tension glaucoma: is it different from primary open-angle glaucoma? Curr Opin Ophthalmol. 2008;19(2):85-8.

6. Chen Y, Hughes G, Chen X, Qian S, Cao W, Wang L, et al. genetic variants associated with different risks for high tension glaucoma and normal tension glaucoma in a chinese population. Invest Ophthalmol Vis Sci. 2015;56(4):2595-600.

7. Leung DY, Kwong YY, Li FC, Tham Cc, Chi Sc, Lam DS. Comparison of the clinical characteristics of normal tension glaucoma patients with pretreatment intraocular pressures in the high-teens and low-teens. Br J Ophthalmol. 2010;94(5):663-5.

8. Cho HK, Kee C. Population-based glaucoma prevalence studies in Asians. Surv Ophthalmol. 2014;59(4):434-47.

9. Rotchford AP, Johnson GJ. Glaucoma in Zulus: a population-based cross-sectional survey in a rural district in South Africa. Arch Ophthalmol. 2002;120(4):471-8.

10. Bonomi L, Marchini G, Marraffa M, Bernardi P, De Franco I, Perfetti S, et al. Prevalence of glaucoma and intraocular pressure distribution in a defined population. The Egna-Neumarkt Study. Ophthalmology. 1998;105(2):209-15. Comment in: Ophthalmology. 2001;108(9):1514.

11. Klein BE, Klein R, Sponsel WE, Franke T, Cantor LB, Martone J, et al. Prevalence of glaucoma. The Beaver Dam Eye Study. Ophthalmology. 1992;99(10):1499-504.

12. Sommer A, Tielsch JM, Katz J, Quigley HA, Gottsch JD, Javitt J, et al. Relationship between intraocular pressure and primary open angle glaucoma among white and black Americans. The Baltimore Eye Survey. Arch Ophthalmol. 1991;109(8):1090-5

13. Bowe A, Grunig M, Schubert J, Demir M, Hoffman V, Kutting F, et al. Circadian variation in arterial blood pressure and glaucomatous optic neuropathy-a systematic review and meta-Analysis. Am J Hypertens. 2015;28(9):1077-82.Comment in: Am J Hypertens. 2015;28(9):1182-3. Am J Hypertens. 2015;28(9):1184-5.

14. Charlson ME, de Moraes CG, Link A, Wells MT, Harmon G, Peterson JC, et al. Nocturna systemic hypotension increases the risk of glaucoma progression. Ophthalmology. 2014;121(10):2004-12. Comment in: Ophthalmology. 2015;122(4):e25-6. Ophthalmology. 2015;122(4):e26-7. Ophthalmology. 2015;122(2):e15. Ophthalmology. 2015; 122(2):e15-6.

15. Lee J, Choi J, Jeong D, Kim S, Kook MS. Relationship between daytime variability of blood pressure or ocular perfusion pressure and glaucomatous visual field progression. Am J Ophthalmol. 2015;160(3):522-37. Comment in: Am J Ophthalmol. 2015; 160(4):844-5. Am J Ophthalmol. 2015;160(4):845-6.

16. Sung KR, Lee S, Park SB, Choi J, Kim ST, Yun SY, Kang SY, et al. Twenty-four hour ocular perfusion pressure fluctuation and risk of normal-tension glaucoma progression. Invest Ophthalmol Vis Sci. 2009;50(11):5266-74.

17. Remme WJ. The sympathetic nervous system and ischaemic heart disease. Eur Heart J. 1998;19 Suppl F:F62-71.

18. Riccadonna M, Covi G, Pancera P, Presciuttini B, Babighian S, Perfetti S, et al. Autonomic system activity and 24-hour blood pressure variations in subjects with normal-and high-tension glaucoma. J Glaucoma. 2003;12(2):156-63.

19. Wierzbowska J, Wierzbowski R, Stankiewicz A, Siesky B, Harris A. Cardiac autonomic dysfunction in patients with normal tension glaucoma: 24 -h heart rate and blood pressure variability analysis. Br J Ophthalmol. 2012;96(5):624-8.

20. Park HY, Park SH, Park CK. Central visual field progression in normal-tension glaucoma patients with autonomic dysfunction. Invest Ophthalmol Vis Sci. 2014;55(4):2557-63.

21. Konieczka K, Ritch R, Traverso CE, Kim DM, Kook MS, Gallino A, et al. Flammer syndrome EPMA J. 2014;5(1):11

22. Flammer J, Konieczka K, Flammer AJ. The primary vascular dysregulation syndrome: implications for eye diseases. EPMA J. 2013;4(1):14

23. Flammer J, Mozaffarieh M. What is the present pathogenetic concept of glaucomatous optic neuropathy? Surv Ophthalmol. 2007;52 Suppl 2:S162-73.

24. Sergi M, Salerno DE, Rizzi M, Blini M, ANdreoli A, Messenio D, et al. Prevalence of normal tension glaucoma in obstructive sleep apnea syndrome patients. J Glaucoma. 2007;16(1):42-6.

25. Lin PW, Friedman M, Lin HC, Chang HW, Wilson M, Lin MC. Normal tension glaucoma in patients with obstructive sleep apnea/hypopnea syndrome. J Glaucoma. 2011;20(9): 553-8.

26. Cecchi E, Liotta AA, Gori AM, Valente S, Giglioli C, Lazzeri C, et al. Comparison of hemorheological variables in ST-elevation myocardial infarction versus those in non-ST-elevation myocardial infarction or unstable angina pectoris. Am J Cardiol. 2008;102(2):125-8.

27. Velcheva I, Antonova N, Titianova E, Damianov P, Dimitrov N, Dimitrova V. Hemorheological disturbances in cerebrovascular diseases. Clin Hemorheol Microcirc. 2008;39(1-4): 391-6.

28. Khodabandehlou T, Le Devehat C. Hemorheological disturbances as a marker of diabetic foot syndrome deterioration. Clin Hemorheol Microcirc. 2004;30(3-4):219-23.

29. Hamard P, Hamard H, Dufaux J, Quesnot S. Optic nerve head blood flow using a laser Doppler velocimeter and haemorheology in primary open angle glaucoma and normal pressure glaucoma. Br J Ophthalmol. 1994;78(6):449-53. 
30. Cheng HC, Chan CM, Yeh SI, Yu JH, Liu DZ. The hemorheological mechanisms in normal tension glaucoma. Curr Eye Res. 2011:36(7):647-53.

31. Morgan WH, Chauhan BC, Yu DY, Cringle SJ, Alder VA, House PH. Optic disc movement with variations in intraocular and cerebrospinal fluid pressure. Invest Ophthalmol Vis Sci. 2002;43(10):3236-42.

32. Fleischman $D$, Allingham RR. The role of cerebrospinal fluid pressure in glaucoma and other ophthalmic diseases: A review. Saudi J Ophthalmol. 2013;27(2):97-106.

33. Ren R, Jonas JB, Tian G, Zhen Y, Ma K, Li S, Wang H, et al. Cerebrospinal fluid pressure in glaucoma: a prospective study. Ophthalmology. 2010;117(2):259-66.

34. Ren $R$, Wang N, Zhang $X$, Cui $T$, Jonas JB. Trans-lamina cribrosa pressure difference correlated with neuroretinal rim area in glaucoma. Graefes Arch Clin Exp Ophthalmol. 2011:249(7):1057-63.

35. Siaudvytyte L, Januleviciene I, Daveckaite A, Ragauskas A, Bartusis L, Kucinoviene J, et al. Literature review and meta-analysis of translaminar pressure difference in open-angle glaucoma. Eye (Lond). 2015;29(10):1242-50.

36. Bianchi-Marzoli S, Rizzo JF, 3rd, Brancato R, Lessell S. Quantitative analysis of optic disc cupping in compressive optic neuropathy. Ophthalmology. 1995;102(3):436-40.

37. O'Neill EC, Danesh-Meyer HV, Connell PP, Trounce IA, Coote MA, Mackey DA, et al. The optic nerve head in acquired optic neuropathies. Nat Rev Neurol. 2010;6(4):221-36.

38. O'Neill EC, Mackey DA, Connell PP, Hewitt AW, Danesh-Meyer HV, Crowston JG. The optic nerve head in hereditary optic neuropathies. Nat Rev Neurol. 2009;5(5):277-87.

39. Piette SD, Sergott RC. Pathological optic-disc cupping. Curr Opin Ophthalmol. 2006; 17(1):1-6.

40. Emanuel ME, Gedde SJ. Indications for a systemic work-up in glaucoma. Can J Ophthalmol. 2014:49(6):506-11.

41. Greenfield DS, Siatkowski RM, Glaser JS, Schatz NJ, Parrish RK $2^{\text {nd }}$. The cupped disc. Who needs neuroimaging? Ophthalmology. 1998;105(10):1866-74.

42. Brusini $P$, Miani F, Tosoni C. Corneal thickness in glaucoma: an important parameter? Acta Ophthalmol Scand Suppl. 2000(232):41-2.

43. Brandt JD, Beiser JA, Kass MA, Gordon MO. Central corneal thickness in the Ocular Hypertension Treatment Study (OHTS). Ophthalmology. 2001;108(10):1779-88

44. Cao KY, Kapasi M, Betchkal JA, Birt CM. Relationship between central corneal thickness and progression of visual field loss in patients with open-angle glaucoma. Can J Ophthalmol. 2012;47(2):155-8.

45. Choi HJ, Kim DM, Hwang SS. Relationship between central corneal thickness and localized retinal nerve fiber layer defect in normal-tension glaucoma. J Glaucoma. 2006;15(2):120-3.

46. Sakata R, Aihara M, Murata H, Mayama C, Tomidokoro A, Iwase A, et al. Contributing factors for progression of visual field loss in normal-tension glaucoma patients with medical treatment. J Glaucoma. 2013;22(3):250-4

47. Congdon NG, Broman AT, Bandeen-Roche K, et al. Central corneal thickness and corneal hysteresis associated with glaucoma damage. Am J Ophthalmol. 2006;141(5): 868-75.

48. Deol M, Taylor DA, Radcliffe NM. Corneal hysteresis and its relevance to glaucoma. Curr Opin Ophthalmol. 2015;26(2):96-102.

49. Wells AP, Garway-Heath DF, Poostchi A, Wong T, Chan KC, Sachdev N. Corneal hysteresis but not corneal thickness correlates with optic nerve surface compliance in glaucoma patients. Invest Ophthalmol Vis Sci. 2008:49(8):3262-8.

50. Kaushik S, Pandav SS, Banger A, AggarawalK, Gupta A. Relationship between cornea biomechanical properties, central corneal thickness, and intraocular pressure across the spectrum of glaucoma. Am J Ophthalmol. 2012;153(5):840-9 e2.

51. Park JH, Jun RM, Choi KR. Significance of corneal biomechanical properties in patients with progressive normal-tension glaucoma. Br J Ophthalmol. 2015;99(6):746-51

52. Park HY, Jung KI, Na KS, ParkSH, ParkCK. Visual field characteristics in normal-tension glaucoma patients with autonomic dysfunction and abnormal peripheral microcirculation. Am J Ophthalmol. 2012;154(3):466-75 e1.

53. Caprioli J, Spaeth GL. Comparison of the optic nerve head in high- and low-tension glaucoma. Arch Ophthalmol. 1985;103(8):1145-9.

54. Eid TE, Spaeth GL, Moster MR, Augsburger JJ. Quantitative differences between the optic nerve head and peripapillary retina in low-tension and high-tension primary open-angle glaucoma. Am J Ophthalmol. 1997;124(6):805-13

55. Adlina AR, Alisa-Victoria K, Shatriah I, Liz-Sharmini AT, Ahmada MS. Optic disc topography in Malay patients with normal-tension glaucoma and primary open-angle glaucoma. Clin Ophthalmol. 2014:8:2533-9.

56. Kiriyama N, Ando A, Fukui C, Nambu H, Nishikawa M, Terauchi H, Kuwahara A, et al. A comparison of optic disc topographic parameters in patients with primary open angle glaucoma, normal tension glaucoma, and ocular hypertension. Graefes Arch Clin Exp Ophthalmol. 2003;241(7):541-5.

57. Seong M, Sung KR, Choi EH, Kang SY, Cho JW, Um TW, et al. Macular and peripapillary retinal nerve fiber layer measurements by spectral domain optical coherence tomography in normal-tension glaucoma. Invest Ophthalmol Vis Sci. 2010;51(3):1446-52.

58. Kim NR, Hong S, Kim JH, Rho SS, Seong GJ, Kim CY. Comparison of macular ganglion cell complex thickness by Fourier-domain OCT in normal tension glaucoma and primary open-angle glaucoma. J Glaucoma. 2013:22(2):133-9.

59. Jung YH, Park HY, Jung Kl, Park CK. Comparison of prelaminar thickness between primary open angle glaucoma and normal tension glaucoma patients. PLoS One. 2015; 10(3):e0120634
60. Park HY, Jeon SH, Park CK. Enhanced depth imaging detects lamina cribrosa thickness differences in normal tension glaucoma and primary open-angle glaucoma. Ophthalmology. 2012;119(1):10-20.

61. Kwun Y, Han JC, Kee C. Comparison of lamina cribrosa thickness in normal tension glaucoma patients with unilateral visual field defect. Am J Ophthalmol. 2015;159(3): $512-8$ e1.

62. Omodaka K, Horii T, Takahashi S, Kikawa, Matsumoto A, Shiga Y, et al. 3D evaluation of the lamina cribrosa with swept-source optical coherence tomography in normal tension glaucoma. PLoS One. 2015;10(4):e0122347.

63. Park HY, Choi SI, Choi JA, Park CK. Disc Torsion and Vertical Disc Tilt Are Related to Subfoveal Scleral Thickness in Open-Angle Glaucoma Patients With Myopia. Invest Ophthalmol Vis Sci. 2015;56(8):4927-35.

64. Wang W, Zhang X. Choroidal thickness and primary open-angle glaucoma: a cross-sectional study and meta-analysis. Invest Ophthalmol Vis Sci. 2014;55(9):6007-14.

65. Jiang $R$, Wang $Y X$, Wei WB, Xu L, Jonas JB. Peripapillary choroidal thickness in adult chinese: The Beijing Eye Study. Invest Ophthalmol Vis Sci. 2015;56(6):4045-52.

66. Zhang C, Tatham AJ, Medeiros FA, Zangwill LM, Yang Z, Weinreb RN. Assessment of choroidal thickness in healthy and glaucomatous eyes using swept source optical coherence tomography. PLoS One. 2014;9(10):e109683.

67. Hirooka K, Tenkumo K, Fujiwara A, Baba T, Sato S, Shiraga F. Evaluation of peripapillary choroidal thickness in patients with normal-tension glaucoma. BMC Ophthalmol. 2012;12:29.

68. Park HY, Lee NY, Shin HY, Park CK. Analysis of macular and peripapillary choroidal thickness in glaucoma patients by enhanced depth imaging optical coherence tomography. J Glaucoma. 2014;23(4):225-31.

69. De Moraes CG, Juthani VJ, Liebmann JM, Teng CC, Tello C, Susanna R Jr, et al. Risk factors for visual field progression in treated glaucoma. Arch Ophthalmol. 2011;129(5):562-8.

70. De Moraes CG, Prata TS, Liebmann CA, Tello C, Ritch R, Liebmann JM. Spatially consistent, localized visual field loss before and after disc hemorrhage. Invest Ophthalmol Vis Sci. 2009;50(10):4727-33

71. Kim SH, Park KH. The relationship between recurrent optic disc hemorrhage and glaucoma progression. Ophthalmology. 2006;113(4):598-602

72. Leske MC, Heijl A, Hussein M, Bengtsson B, Hyman L, Komaroff E; Early Manifest Glaucoma Trial Group. Factors for glaucoma progression and the effect of treatment: the early manifest glaucoma trial. Arch Ophthalmol. 2003;121(1):48-56.

73. Sugiyama K, Tomita G, Kitazawa Y, Onda E, Shinohara H, Park KH. The associations of optic disc hemorrhage with retinal nerve fiber layer defect and peripapillary atrophy in normal-tension glaucoma. Ophthalmology. 1997;104(11):1926-33.

74. Furlanetto RL, De Moraes CG, Teng CC, Liebman JM, Greenfield DS, Gardiner SK, Ritch R, Krupin T; Low-Pressure Glaucoma Treatment Study Group. Risk factors for optic disc hemorrhage in the low-pressure glaucoma treatment study. Am J Ophthalmol. 2014; 157(5):945-52.

75. Nitta K, Sugiyama K, Higashide T, Ohkubo S, Tanahashi T, Kitazawa Y. Does the enlargement of retinal nerve fiber layer defects relate to disc hemorrhage or progressive visual field loss in normal-tension glaucoma? J Glaucoma. 2011;20(3):189-95.Comment in: J Glaucoma. 2012;21(4):275-6.

76. Lee EJ, Kim TW, Kim M, Girard MJ, Maria JM, Weinreb RN. Recent structural alteration of the peripheral lamina cribrosa near the location of disc hemorrhage in glaucoma. Invest Ophthalmol Vis Sci. 2014;55(4):2805-15.

77. Caprioli J, Spaeth GL. Comparison of visual field defects in the low-tension glaucomas with those in the high-tension glaucomas. Am J Ophthalmol. 1984;97(6):730-7.

78. Thonginnetra O, Greenstein VC, Chu D, Liebmann JM, Ritch R, Hood DC. Normal versus high tension glaucoma: a comparison of functional and structural defects. J Glaucoma. 2010;19(3):151-7.

79. Curcio CA, Allen KA. Topography of ganglion cells in human retina. J Comp Neurol. 1990;300(1):5-25.

80. Traynis I, De Moraes CG, Raza AS, Liebmann JM, Ritch R, Hood DC. Prevalence and nature of early glaucomatous defects in the central 10 degrees of the visual field. JAMA Ophthalmol. 2014:132(3):291-7.

81. Cho HK, Kee C. Comparison of the progression rates of the superior, inferior, and both hemifield defects in normal-tension glaucoma patients. Am J Ophthalmol. 2012;154(6): 958-68 e1.

82. Cho HK, Lee J, Lee M, Kee C. Initial central scotomas vs peripheral scotomas in normal-tension glaucoma: clinical characteristics and progression rates. Eye (Lond). 2014;28(3):303-11.

83. Kim KN, Jeoung JW, Park KH, Kim DM, Ritch R. Relationship between preferred sleeping position and asymmetric visual field loss in open-angle glaucoma patients. Am J Ophthalmol. 2014;157(3):739-45. Comment in: Am J Ophthalmol. 2014;157(6):1327-8. Am J Ophthalmol. 2014;157(6):1327.

84. Lee J, Kong M, Kim J, Kee C Comparison of visual field progression between relatively low and high intraocular pressure groups in normal tension glaucoma patients. J Glaucoma. 2014;23(8):553-60.

85. Drance S, Anderson DR, Schulzer M; Collaborative Normal-Tension Glaucoma Study G. Risk factors for progression of visual field abnormalities in normal-tension glaucoma. Am J Ophthalmol. 2001;131(6):699-708.

86. Ernest PJ, Schouten JS, Beckers HJ, Hendrikse F, Prins MH, Webers CA. An evidence-based review of prognostic factors for glaucomatous visual field progression. Ophthalmology. 2013;120(3):512-9. 
87. Sohn SW, Song JS, Kee C. Influence of the extent of myopia on the progression of normal-tension glaucoma. Am J Ophthalmol. 2010;149(5):831-8.

88. De Moraes CG, Liebmann JM, Liebmann CA, Susanna R Jr, Tello C, Ritch R. Visual field progression outcomes in glaucoma subtypes. Acta Ophthalmol. 2013;91(3):288-93.

89. Comparison of glaucomatous progression between untreated patients with normal-tension glaucoma and patients with therapeutically reduced intraocular pressures. Collaborative Normal-Tension Glaucoma Study Group. Am J Ophthalmol. 1998;126(4):487-97.Erratum in: Am J Ophthalmol. 1999;127(1):120. Comment in: Am J Ophthalmol. 1998;126(4):578-81. Am J Ophthalmol. 1999;127(5):623-5. Am J Ophthalmol. 1999;127(5):625-6. Am J Ophthalmol. 1999;128(6):776-7.

90. The effectiveness of intraocular pressure reduction in the treatment of normal-tension glaucoma. Collaborative Normal-Tension Glaucoma Study Group. Am J Ophthalmol. 1998;126(4):498-505. Comment in: Am J Ophthalmol. 1998;126(4):578-81. Am J Ophthalmol. 1999;127(5):623-5.

91. Cheng JW, Cai JP, Wei RL. Meta-analysis of medical intervention for normal tension glaucoma. Ophthalmology. 2009;116(7):1243-9.

92. Fung AT, Reid SE, Jones MP, Healey PR, McCluskey PJ, Craig JC. Meta-analysis of randomised controlled trials comparing latanoprost with brimonidine in the treatment of open-angle glaucoma, ocular hypertension or normal-tension glaucoma. Br J Ophthalmol. 2007;91(1):62-8.

93. Kim TW, Kim M, Lee EJ, Jeoung JW, Park KH. Intraocular pressure-lowering efficacy of dorzolamide/timolol fixed combination in normal-tension glaucoma. J Glaucoma. 2014;23(5):329-32.

94. Kim JM, Kim TW, Kim CY, Kim HK,Park KH. Comparison of the intraocular pressure-lowering effect and safety of brimonidine/timolol fixed combination and 0.5\% timolol in normal-tension glaucoma patients. Jpn J Ophthalmol. 2016;60(1):20-6.

95. Krupin T, Liebmann JM, Greenfield DS, Ritch R, Gardiner s; Low-Pressure Glaucoma Study Group. A randomized trial of brimonidine versus timolol in preserving visual function: results from the Low-Pressure Glaucoma Treatment Study. Am J Ophthalmol. 2011:151(4):671-81. Erratum in: Am J Ophthalmol. 2011:151(6):1108.

96. Hayreh SS, Podhajsky P, Zimmerman MB. Beta-blocker eyedrops and nocturnal arterial hypotension. Am J Ophthalmol. 1999;128(3):301-9.

97. Pinar-Sueiro S, Urcola H, Rivas MA, Vecino E. Prevention of retinal ganglion cell swelling by systemic brimonidine in a rat experimental glaucoma model. Clin Experiment Ophthalmol. 2011;39(8):799-807.

98. Lindsey JD, Duong-Polk KX, Hammond D, Chindasub P, Leung CK, Weinreb RN. Differential protection of injured retinal ganglion cell dendrites by brimonidine. Invest Ophthalmol Vis Sci. 2015;56(3):1789-804.

99. Guo L, Salt TE, Maass A, Luong V, Moss SE, Fitzke FW, et al. Assessment of neuroprotective effects of glutamate modulation on glaucoma-related retinal ganglion cell apoptosis in vivo. Invest Ophthalmol Vis Sci. 2006;47(2):626-33.

100. Johnson JW, Kotermanski SE. Mechanism of action of memantine. Curr Opin Pharmacol. 2006;6(1):61-7.

101. Hare WA, WoldeMussie E, Lai RK, Ton H, Ruiz G, Chung T, et al. Efficacy and safety of memantine treatment for reduction of changes associated with experimental glaucoma in monkey, I: Functional measures. Invest Ophthalmol Vis Sci. 2004;45(8): 2625-39. Erratum in: Invest Ophthalmol Vis Sci. 2004;45(9):2878.

102. Yucel YH, Gupta N, Zhang Q, Mizisin AP, Kalichman MW, Weinreb RN. Memantine protects neurons from shrinkage in the lateral geniculate nucleus in experimental glaucoma. Arch Ophthalmol. 2006;124(2):217-25.

103. Hare WA, WoldeMussie E, Weinreb RN, Ton H, Ruiz G, Wijono M, et al. Efficacy and safety of memantine treatment for reduction of changes associated with experimental glaucoma in monkey, II: Structural measures. Invest Ophthalmol Vis Sci. 2004;45(8): 2640-51.

104. Osborne NN. Recent clinical findings with memantine should not mean that the idea of neuroprotection in glaucoma is abandoned. Acta Ophthalmol. 2009;87(4):450-4

105. Allergan reports fourth quarter operating results [press release]. Irvine; CA: Alergan Inc; jan 30 2008. [cited 2008 Jan 30] Available from: agn360.client.shareholder.com/ releasedetail.cfm?ReleaselD $=290764$.
106. Diamond BJ, Bailey MR. Ginkgo biloba: indications, mechanisms, and safety. Psychiatr Clin North Am. 2013;36(1):73-83.

107. Yin B, Xu Y, Wei R, Luo B. Ginkgo biloba on focal cerebral ischemia: a systematic review and meta-analysis. Am J Chin Med. 2014;42(4):769-83.

108. Quaranta L, Bettelli S, Uva MG, Semeraro F, Turano R, Gandolfo E. Effect of Ginkgo biloba extract on preexisting visual field damage in normal tension glaucoma. Ophthalmology. 2003;110(2):359-62; discussion 62-4.

109. Lee J, Sohn SW, Kee C. Effect of Ginkgo biloba extract on visual field progression in normal tension glaucoma. J Glaucoma. 2013;22(9):780-4.

110. Guo X, Kong X, Huang R, Jin L,I Ding X, He M, et al. Effect of Ginkgo biloba on visual field and contrast sensitivity in Chinese patients with normal tension glaucoma: a randomized, crossover clinical trial. Invest Ophthalmol Vis Sci. 2014;55(1):110-6. Erratum in: Invest Ophthalmol Vis Sci. 2014;55(4):2315. Comment in: Invest Ophthalmol Vis Sci. 2014;55(4):2418. Invest Ophthalmol Vis Sci. 2014;55(4):2417.

111. Nicolai SP, Kruidenier LM, Bendermacher BL, Prins MH, Stokmans RA, Boorks PP, et al. Ginkgo biloba for intermittent claudication. Cochrane Database Syst Rev. 2013;6: CD006888.

112. Hilton MP, Zimmermann EF, Hunt WT. Ginkgo biloba for tinnitus. Cochrane Database Syst Rev. 2013;3:CD003852.

113. He D, Zhou H, Guo D, Hao Z, Wu B. Pharmacologic treatment for memory disorder in multiple sclerosis. Cochrane Database Syst Rev. 2011(10):CD008876.

114. Evans JR. Ginkgo biloba extract for age-related macular degeneration. Cochrane Database Syst Rev. 2013;1:CD001775.

115. Yang M, Xu DD, Zhang Y, Liu X, Hoevn R, Cho WC. A systematic review on natural medicines for the prevention and treatment of Alzheimer's disease with meta-analyses of intervention effect of ginkgo. Am J Chin Med. 2014;42(3):505-21.

116. Michalk F, Michelson G, Harazny J, Werner U, Daniel WG, Werner D. Single-dose nimodipine normalizes impaired retinal circulation in normal tension glaucoma. J Glaucoma. 2004;13(2):158-62

117. Luksch A, Rainer G, Koyuncu D, Ehrlich P, Maca T, Gschwandtner ME, et al. Effect of nimodipine on ocular blood flow and colour contrast sensitivity in patients with normal tension glaucoma. Br J Ophthalmol. 2005;89(1):21-5.

118. Aydin B, Onol M, Hondur A, Kaya MG, Ozdemir H, Cengel A, et al. The effect of oral magnesium therapy on visual field and ocular blood flow in normotensive glaucoma. Eur J Ophthalmol. 2010;20(1):131-5.

119. Choi HW, Tian M, Manohar M, Harraz MM, Park SW, Schroeder FC, et al. Human GAPDH Is a Target of Aspirin's Primary Metabolite Salicylic Acid and Its Derivatives. PLoS One. 2015;10(11):e0143447.

120. Kim M, Kim DM, Park KH, Kim TW, Jeoung JW, Kim SH. Intraocular pressure reduction with topical medications and progression of normal-tension glaucoma: a 12-year mean follow-up study. Acta Ophthalmol. 2013;91(4):e270-5.

121. Komori S, Ishida K, Yamamoto T. Results of long-term monitoring of normal-tension glaucoma patients receiving medical therapy: results of an 18-year follow-up. Graefes Arch Clin Exp Ophthalmol. 2014:252(12):1963-70.

122. Lee JW, Ho WL, Chan J, Lai JS. Efficacy of selective laser trabeculoplasty for normal tension glaucoma: 1 year results. BMC Ophthalmol. 2015;15(1):1.

123. Iverson SM, Schultz SK, Shi W, Feuer WJ, Greenfield DS. Effectiveness of Single-Digit IOP targets on decreasing global and localized visual field progression after filtration surgery in eyes with progressive normal-tension glaucoma. J Glaucoma. 2015. [Epub ahead of print]

124. Schultz SK, Iverson SM, Shi W, Greenfield DS. Safety and efficacy of achieving single-digit intraocular pressure targets with filtration surgery in eyes with progressive normal-tension glaucoma. J Glaucoma. 2016;25(2):217-22

125. Jayaram H, Strouthidis NG, Kamal DS. Trabeculectomy for normal tension glaucoma: outcomes using the Moorfields Safer Surgery technique. Br J Ophthalmol. 2016; 100(3):332-8.

126. Suominen S, Harju M, Kurvinen L, Vesti E. Deep sclerectomy in normal-tension glaucoma with and without mitomycin-c. Acta Ophthalmol. 2014;92(7):701-6. 